\title{
Computerized assessment of competence- related abilities in living liver donors: the Adult-to-Adult Living Donor Liver Transplantation Cohort Study
}

Freeman J, Emond J, Gillespie BW, Appelbaum PS, Weinrieb R, Hill-Callahan P, Gordon EJ, Terrault N, Trotter J, Ashworth A, Dew MA, Pruett T, the A2ALL Study Group. Computerized assessment of competence-related abilities in living liver donors: the Adult-to-Adult Living Donor Liver Transplantation Cohort Study (A2ALL).

Abstract: Background: Despite its importance, determination of competence to consent to organ donation varies widely based on local standards. We piloted a new tool to aid transplant centers in donor assessment.

Methods: We assessed competence-related abilities among potential living liver donors (LDs) in the nine-center A2ALL study. Prospective LDs viewed an educational video and were queried to assess Understanding, Appreciation, Reasoning, and ability to express a Final Choice using the MacArthur Competence Assessment Tool for Clinical Research, adapted for computerized administration in LDs ("MacLiver"). Videotaped responses were scored by a clinical neuropsychologist (JF).

Results: Ninety-three LDs were assessed. Mean (standard deviation; domain maximum) scores were as follows: Understanding: 18.1 (2.6; $\max =22)$, Appreciation: $5.1(1.0 ; \max =6)$, Reasoning: $3.1(0.8$; $\max =4)$, and Final Choice: $3.8(0.5 ; \max =4)$. Scores did not differ by demographics, relationship to the recipient, eligibility to donate, or eventual donation $(p>0.4)$. Higher education was associated with greater Understanding $(\mathrm{p}=0.004)$ and Reasoning $(\mathrm{p}=0.03)$.

Conclusion: Standardized, computerized education with independent ratings of responses may (1) alert the clinical staff to potential donors who may not be competent to donate and (2) highlight areas needing further assessment and education, leading to better informed decision making.

\section{Jason Freeman ${ }^{\mathrm{a}}$, Jean Emond ${ }^{\mathrm{b}}$, Brenda W. Gillespie ${ }^{c}$, Paul S. Appelbaum $^{d}$, Robert Weinrieb ${ }^{\mathrm{e}}$, Peg Hill-Callahan ${ }^{f}$, Elisa J. Gordon $^{\mathrm{g}}$, Norah Terrault ${ }^{\mathrm{h}}$, James Trotter $^{\mathrm{i}, \mathrm{m}}$, April Ashworth ${ }^{\mathrm{j}}$, Mary Amanda Dewk', Timothy Pruett' and the A2ALL Study Group ${ }^{1}$}

${ }^{a}$ Department of Psychiatry and Neurobehavioral Sciences, University of Virginia, Charlottesville, VA, 'Department of Surgery, Columbia University Medical Center, New York, NY, 'Department of Biostatistics, University of Michigan, Ann Arbor, MI, dDepartment of Psychiatry, Columbia University Medical Center, New York, NY, eDepartment of Psychiatry, University of Pennsylvania, Philadelphia, PA, ${ }^{\dagger}$ Arbor Research Collaborative for Health, Ann Arbor, MI, ${ }^{9}$ Center for Healthcare Studies and Comprehensive Transplant Center, Northwestern University, Chicago, IL, hDepartment of Medicine, University of California at San Francisco, San Francisco, CA, 'Department of Surgery, University of Colorado, Aurora, CO, 'Department of Transplant Surgery, Virginia Commonwealth University Medical Center, Richmond, VA, ${ }^{k}$ Department of Psychiatry, University of Pittsburgh School of Medicine and Medical Center, Pittsburgh, PA, 'Department of Transplant Surgery, University of Minnesota, Minneapolis, MN and ${ }^{\mathrm{m}}$ Current address: Department of Medicine, Baylor University Medical Center, Dallas, TX, USA

Key words: comprehension - ethics informed consent - living donation MacArthur Competence Assessment Tool for Clinical Research - transplantation

Corresponding author: Jason R. Freeman, PhD, Department of Psychiatry and Neurobehavioral Sciences, University of Virginia Health System, Neurocognitive Assessment Lab, PO Box 800203 , Charlottesville, VA 22908-0203, USA. 


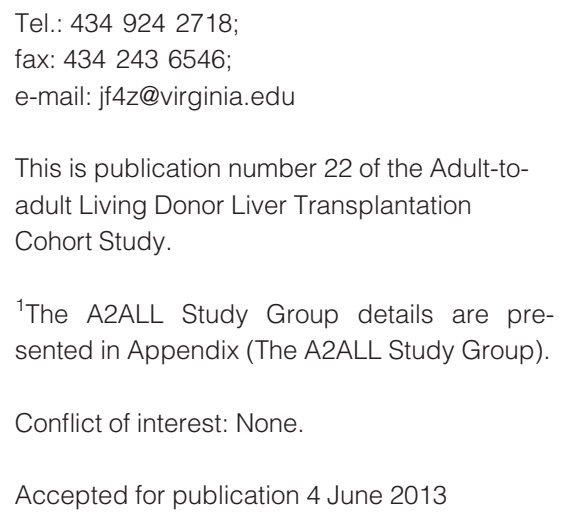

Adult-to-adult living donor liver transplantation (LDLT) is an alternative to deceased donor transplantation that can reduce waiting time and improve outcomes (1). This procedure presents difficult choices to patients and families, as it requires the living donor (LD) to undergo an operation with an estimated risk 10 -fold that of donating a kidney $(2,3)$. The death of an LD immediately after donation in 2002, and two more donor deaths in 2010 (4), led to increased scrutiny of the living donation process. In 2002, the Advisory Committee on Organ Transplantation (ACOT) developed 18 consensus guidelines to make the process as "safe and effective as possible, for both the living organ donor and the recipient," while maintaining the efficacy of living donation and transplantation (http://organdonor.gov/legislation/acotrecs118.html). Foremost among these guidelines is that suitable donors be competent. Subsequently, international conferences organized by The Transplantation Society on care of live kidney (2003) and extrarenal (2005) donors reaffirmed that live organ donors must be competent (5-7). Competence to agree to an LDLT entails several abilities, including comprehension, appreciation, reasoning, and decision making that have been defined in the literature and have become the basis for objective evaluation in both medical and legal settings $(8,9)$. Despite consensus regarding the requirement of competence, there is no standard metric for measuring competence, and the process of assessment varies widely based on local standards (10-12).

The Adult-to-Adult Living Donor Liver Transplantation Cohort Study (A2ALL), a consortium of nine U.S. transplant centers tasked to study adult-to-adult LDLT between 2002 and 2009, included potential donors and recipients in a retrospective (1998-2003) and prospective (2004-2009) study of clinical practice and outcomes. During the retrospective study (13), we recognized that the nine centers did not assess competence-related abilities uniformly. Based on the competence domains noted above, we adapted the MacArthur Competence Assessment Tool for Clinical Research (MacCAT-CR) for LDs ("MacLiver") to provide information about the living donation process in a standardized computer format and query the subject's ability to comprehend and make choices. We sought to provide an initial competence screening that could inform the transplant staff of areas of lower comprehension in potential donors so that educational efforts or evaluations could be appropriately targeted.

The specific goals of this study were to assess the inter-rater reliability of MacLiver scoring, develop preliminary normative distributions for domainspecific scores, and assess covariate effects on these scores. The longer-term goal was to assess this tool for use in clinical practice.

\section{Participants and methods}

\section{A2ALL cohort study and methods}

Participant enrollment into the prospective arm of A2ALL has been described elsewhere (14). In brief, all prospective LDs were eligible. On the day the prospective LD was first evaluated at the transplant center, the study intervention was explained and the opportunity to enroll was offered. Following enrollment, the MacLiver was the first centerprovided educational material given and was given only at the start of the first visit. All study procedures were approved by the institutional review board (IRB) at each study site and at the data coordinating center (DCC), and written informed consent was obtained from all participants. We note that the requirement of informed consent for this study guaranteed a level of competence for study participants. 
The MacArthur Competence Assessment Tool for Clinical Research

The MacCAT-CR is a structured format to assess competence of participants in clinical research (15) that can be adapted for a variety of research settings. It is widely used to assess patients in whom competence is uncertain, such as those with Alzheimer's disease or psychiatric disorders $(16,17)$, and its psychometric properties are well established (18). The MacCAT-CR is typically designed for a live interview setting. However, in adapting the MacCAT-CR for the LD setting, it was modified into a computer-administered presentation to provide a standardized education and assessment format at the nine A2ALL clinical centers and was given the name MacLiver.

The script of the educational component was created by the members of the A2ALL consortium to meet ACOT guidelines for information about the donation process, risks, and outcomes to disclose to prospective LDs as part of the informed consent process. Based on the script, Paul Appelbaum, MD, coauthor of the MacCAT-CR, assisted in generating the MacLiver to specifically (i) provide standardized education and (ii) uniformly assess competence in the prospective LD population. The MacLiver script and the comprehension questions (see SDC, Appendix), read by professional actors, were produced and adapted for video presentation on a tablet computer by Clinaero, Inc. (Bellevue, WA, USA; www.clinaero.com).

The tablet computer presentation included individual modules, each containing a short educational lecture immediately followed by a question/answer session where the potential LDs' answers were captured by a built-in microphone and camera. The modules comprised the MacLiver competence domains: understanding the donor evaluation process, understanding the risks and benefits of donation, understanding the right to refuse without consequence, appreciating the impact of donation, expressing a clear decision to move forward or not, and providing clear reasoning for that decision. Responses were uploaded from the tablets to Clinaero, Inc., which forwarded the files to the study psychologist (JF) for scoring, as described below.

Due to a combination of problems including clinic logistics (primarily the earlier arrival time required to take the MacLiver before clinical visits), Clinaero software problems, and patient refusals, only 169 of $721(23 \%)$ LDs participated in the electronic portion of the data collection. Of these, 31 files had insufficient recorded responses (fewer than 13 of 18 responses) and 45 were not recovered from the tablets, leaving 93 scorable files. Of these, 76 contained both audio and video information (AV), while 17 were "audio-only" files due to additional video recording complications. The latter files were coded solely using the audiotaped responses.

\section{Scoring of the MacLiver}

The assessment component of the MacLiver encompassed 18 questions categorized into four domains. Understanding comprised four subdomains: knowledge of the components of the prospective LD evaluation, the purpose of the MacLiver evaluation, the possible risks and benefits, and understanding the right to terminate the evaluation process at any time without repercussion (11 questions). Appreciation reflected how the risks and benefits could specifically impact the life and well-being of the prospective LD (three questions). Reasoning related to the rationale used to make the decision to donate (two questions). Lastly, Final Choice referred to the ability to express a clear decision (two questions). Each question was scored as 2, 1, or 0 points. A score of 2 was assigned when responses indicated good comprehension of all required elements (see SDC, Appendix) and/or reflected good application of the information, including but not limited to that given by the script. A score of 1 was assigned when a key element of information was missing or if an overly vague or concrete answer was provided. Zero points were given for responses that were inaccurate, fully insufficient, or when the respondent could not provide a response.

\section{Clinical donor evaluation process}

Following the MacLiver, prospective LDs underwent center-specific clinical evaluation. The assessment determined mental and physical suitability, including motivation, medical evaluation of overall health, suitability and morphology of the liver, and psychosocial evaluation of competence to consent for donation. Under the A2ALL protocol, acceptance for donation was determined by the local evaluating team using local standards to determine competence and psychosocial stability. The clinical teams evaluating the donors were blinded to the MacLiver assessment. Clinical data elements, including whether the prospective LD was ruled out for donation and the reason for the rule out, were recorded in the A2ALL database.

\section{Post-donation perception of donation items}

For those who donated, we collected data three months post-donation via a standardized sur- 
vey on LDs' perceived preparation for donation, perceived stress about the donation experience, and overall feelings about living donation (19). We compared these items between MacLiver completers and non-completers to determine whether completing the MacLiver predicted their sense of preparedness or feelings about the donation experience.

\section{Data analysis}

Multiple imputation was used to impute the missing items for participants with complete data for at least 13 of the 18 MacLiver items (20-22). Five imputation data sets were generated, and all subsequent analyses were performed by pooling the results from these five data sets. The SAS ${ }^{\mathrm{TM}}$ MI and MIAnalyze procedures were used for the imputation and subsequent analyses. Comparisons between groups were performed using two-sample t-tests for continuous variables, and using chisquare tests for dichotomous variables.

\section{Results}

\section{Study population and demographics}

Table 1 compares demographic and other characteristics of potential donors who did and did not complete the MacLiver. In general, the MacLiver participants were more likely to have education beyond high school and were also more likely to donate, partly because the non-MacLiver group had more contraindications in their potential recipients. Overall, participants had a mean age of 39 years, were nearly equally divided by sex, were predominantly non-Hispanic white, and most had education beyond high school. Nearly two-thirds of participants were biologically related to the candidate. Over half of the evaluated donors did not donate, largely due to medical and anatomical contraindications or changes in the situation of the recipient.

\section{Inter-rater reliability of MacLiver scoring}

For a subset $(n=31)$ of MacLiver recordings, in addition to scoring by the study neuropsychologist (JF), a trained research assistant provided a second independent rating to assess scoring reliability. Of the scorable items, $90 \%$ matched exactly and four items $(1 \%)$ differed by two points (Table 2$)$. Three of the four were for the same prospective LD, the first one co-rated. The differences were due to conflicting conventions on whether LD response material given later in the questioning could be credited to an earlier question. By consensus, subsequent
Table 1. Prospective living donor characteristics

\begin{tabular}{|c|c|c|c|}
\hline Characteristics & $\begin{array}{l}\text { MacLiver }{ }^{a} \\
(n=169) \\
N(\%) \text { or } \\
\text { Mean (SD) }\end{array}$ & $\begin{array}{l}\text { Non-MacLiver } \\
(\mathrm{n}=552) \\
\mathrm{N}(\%) \text { or } \\
\text { Mean (SD) }\end{array}$ & $\mathrm{p}$-Value \\
\hline Age & $39(10.6)$ & 38 (10.6) & 0.33 \\
\hline \multicolumn{4}{|l|}{ Sex } \\
\hline Male & $81(48 \%)$ & 282 (51\%) & \multirow[t]{2}{*}{0.47} \\
\hline Female & $88(52 \%)$ & $270(49 \%)$ & \\
\hline \multicolumn{4}{|l|}{ Ethnicity } \\
\hline Hispanic/Latino & $22(13 \%)$ & $88(16 \%)$ & \multirow[t]{2}{*}{0.35} \\
\hline $\begin{array}{l}\text { Non-Hispanic/ } \\
\text { Non-Latino }\end{array}$ & $147(87 \%)$ & $464(84 \%)$ & \\
\hline \multicolumn{4}{|l|}{ Race } \\
\hline White & 155 (92\%) & 482 (87\%) & \multirow[t]{2}{*}{0.12} \\
\hline Non-white & $14(8 \%)$ & $70(13 \%)$ & \\
\hline \multicolumn{4}{|l|}{ Education } \\
\hline High school or less & 40 (24\%) & $127(23 \%)$ & \multirow[t]{5}{*}{0.001} \\
\hline Technical school & $38(22 \%)$ & $124(22 \%)$ & \\
\hline $\begin{array}{l}\text { Associate/Bachelor } \\
\text { degree }\end{array}$ & $66(39 \%)$ & $144(26 \%)$ & \\
\hline $\begin{array}{l}\text { Post-college graduate } \\
\text { degree }\end{array}$ & $11(7 \%)$ & $53(10 \%)$ & \\
\hline Unknown/missing & $14(8 \%)$ & $104(19 \%)$ & \\
\hline \multirow{2}{*}{\multicolumn{4}{|c|}{$\begin{array}{l}\text { Relatedness to recipient } \\
\text { Biologically related }\end{array}$}} \\
\hline & & & \\
\hline Parent & $8(5 \%)$ & $18(3 \%)$ & \multirow[t]{9}{*}{0.19} \\
\hline Child & $48(28 \%)$ & $189(34 \%)$ & \\
\hline Sibling & $37(22 \%)$ & $84(15 \%)$ & \\
\hline Other biological & $16(9 \%)$ & $51(10 \%)$ & \\
\hline Not biologically related & & & \\
\hline Spouse & $7(4 \%)$ & $40(7 \%)$ & \\
\hline Other non-biological & $46(28 \%)$ & $149(28 \%)$ & \\
\hline Unrelated & $4(2 \%)$ & $3(1 \%)$ & \\
\hline Missing & $3(2 \%)$ & $18(3 \%)$ & \\
\hline \multicolumn{4}{|l|}{ Recipient liver disease } \\
\hline $\mathrm{ETOH}$ & $7(4 \%)$ & $35(6 \%)$ & \\
\hline Not ETOH & $162(96 \%)$ & $517(94 \%)$ & 0.29 \\
\hline \multicolumn{4}{|l|}{ Donation status } \\
\hline Donated & $66(39 \%)$ & $175(32 \%)$ & \multirow[t]{3}{*}{0.03} \\
\hline $\begin{array}{l}\text { Accepted, but did not } \\
\text { donate }^{\text {b }}\end{array}$ & $8(5 \%)$ & $60(11 \%)^{c}$ & \\
\hline Not accepted to donate & $95(56 \%)$ & $316(57 \%)$ & \\
\hline \multicolumn{4}{|l|}{ Reason for non-acceptance } \\
\hline $\begin{array}{l}\text { Medical } \\
\text { contraindications }\end{array}$ & $79(83 \%)$ & $272(86 \%)$ & \multirow[t]{3}{*}{0.75} \\
\hline $\begin{array}{l}\text { Non-medical } \\
\text { contraindications }\end{array}$ & $7(7 \%)$ & $21(7 \%)$ & \\
\hline Declined to donate & $9(9 \%)$ & $23(7 \%)$ & \\
\hline
\end{tabular}

aOf 169 donors who attempted the MacLiver, files for 93 could be recovered and scored.

${ }^{b}$ Reasons for non-donation after acceptance related to recipient condition included the following: candidate condition worsened/removed from transplant consideration, candidate condition improved/removed from transplant consideration, or candidate received a DDLT.

${ }^{\mathrm{c}}$ Excluded one donor who had no accept or decline information.

scoring allowed all information to be credited to any question. For the subsequent analyses of co-rated participants, the average rater scores were used.

When the inter-rater reliability was examined for the four domains, ratings for Appreciation and Reasoning appeared to have more discrepancies 
Table 2. Inter-rater reliability for audio-only and audio plus video, overall, and by MacLiver domain (Understanding, Appreciation, Reasoning, and Final Choice). Table entries are the $\mathrm{n}(\%)$ of scorable items ${ }^{\mathrm{a}}$

\begin{tabular}{|c|c|c|c|c|c|c|c|c|}
\hline \multirow[b]{2}{*}{ Domain } & \multicolumn{4}{|c|}{ Audio only $(\mathrm{n}=8)$} & \multicolumn{4}{|c|}{ Audio + Video $(n=23)$} \\
\hline & Exact match & $\begin{array}{l}1 \text { category } \\
\text { different }\end{array}$ & $\begin{array}{l}2 \text { categories } \\
\text { different }\end{array}$ & Kappa & Exact match & $\begin{array}{l}1 \text { category } \\
\text { different }\end{array}$ & $\begin{array}{c}2 \text { categories } \\
\text { different }\end{array}$ & Kappa \\
\hline Understanding & $76(89 \%)$ & $8(9 \%)$ & $1(1 \%)$ & 0.80 & $226(95 \%)$ & $13(5 \%)$ & 0 & 0.89 \\
\hline Appreciation & $21(91 \%)$ & $2(9 \%)$ & 0 & 0.70 & $53(83 \%)$ & $10(16 \%)$ & $1(1 \%)$ & 0.63 \\
\hline Reasoning & $14(88 \%)$ & $2(12 \%)$ & 0 & 0.76 & $32(76 \%)$ & $9(21 \%)$ & $1(3 \%)$ & 0.54 \\
\hline Final Choice & $15(94 \%)$ & $1(6 \%)$ & 0 & 0.64 & $39(93 \%)$ & $2(5 \%)$ & $1(2 \%)$ & 0.70 \\
\hline All Domains & $126(90 \%)$ & $13(9 \%)$ & $1(1 \%)$ & 0.79 & $350(90 \%)$ & $34(9 \%)$ & $3(1 \%)$ & 0.80 \\
\hline
\end{tabular}

There was no significant difference in the proportion of exact matches between audio only and audio+video for any domain or overall.

than for Understanding and Final Choice, which may indicate greater subjectivity in scoring those components. Differences in total score (maximum total score $=36)$ ranged from -3 to +2 , and raters were not systematically different (paired $t$-test, $\mathrm{df}=30, \mathrm{p}=0.20)$. The absence of video did not affect inter-rater reliability (Table 2), but the presence of video provided information about rare but important contextual influences on participants' responses (e.g., one respondent holding an infant and another being given answers by another person in the room).

\section{Distribution of scores}

Fig. 1a shows boxplots of the score distributions for the four elements of competence (Understanding, Appreciation, Reasoning, and Final Choice), and Fig. 1b shows the subscale scores for each area of Understanding, both for those scored with audio information only (A) and those with both (AV). No significant differences between the A and AV groups were seen for any of the MacLiver scales (two-sample $t$-test, $\mathrm{df}=91$ : Understanding, $\mathrm{p}=0.52$; Appreciation, $\mathrm{p}=0.82 ;$ Reasoning, $\mathrm{p}=0.09 ; \quad$ Final Choice, $\mathrm{p}=0.49$ ). Table 3 gives means and standard deviations for each domain (combining A and $\mathrm{AV})$. The total score is not reported as it is not clinically interpretable; competence can be impaired by poor performance on any one domain even if intact across other domains (14).

Of particular interest are those participants whose scores placed them in the lowest quartile on each of the competence-related abilities (i.e., below the box in Fig. 1a). Although this study did not attempt to establish a quantitative cutoff for adequate performance of competence-related abilities, $18-20 \%$ of participants had scores one standard deviation or more below the mean on Understanding, Appreciation, or Reasoning. The participants falling into these categories did not differ from other participants on the basis of any demographic variable.
There were perfect scores across all prospective LDs in expressing their understanding of the right to refuse further evaluation and to do so without consequence. Near-perfect ability to express a clear choice was also evident across the sample.

Association between MacLiver scores and demographics, relatedness, and donor disposition

Components of the MacLiver were assessed for differences among demographic subgroups (Table 3). No differences were seen by age, sex, ethnicity, race, relationship to the recipient, whether accepted for donation, or completed donation. In contrast, those with more education (Associate's degree and higher vs. technical degree and lower) had significantly higher MacLiver scores for both Understanding and Reasoning. Neither met the criterion for significance after Bonferroni adjustment, but it is unusual that both results were for the same variable.

Relation of MacLiver to local competence assessment

None of the prospective LDs evaluated by the MacLiver were subsequently deemed unable to provide informed consent to living donation by the local standard of psychiatric, psychological, and/ or social worker assessments.

Impact of MacLiver on perceptions of donation

Both the MacLiver and three-month post-donation survey were completed by 36 donors. These donors were as likely as donors who had not completed the MacLiver $(\mathrm{n}=87)$ to report that the information they had received was clear $(94 \%$ vs. $95 \%)$, they were well prepared for donation ( $82 \%$ vs. $83 \%$ ), and they had positive attitudes about living donation in retrospect (79\% vs. 78\%). However, the subset of donors completing the MacLiver was significantly less likely to report that the donation 
Freeman et al.

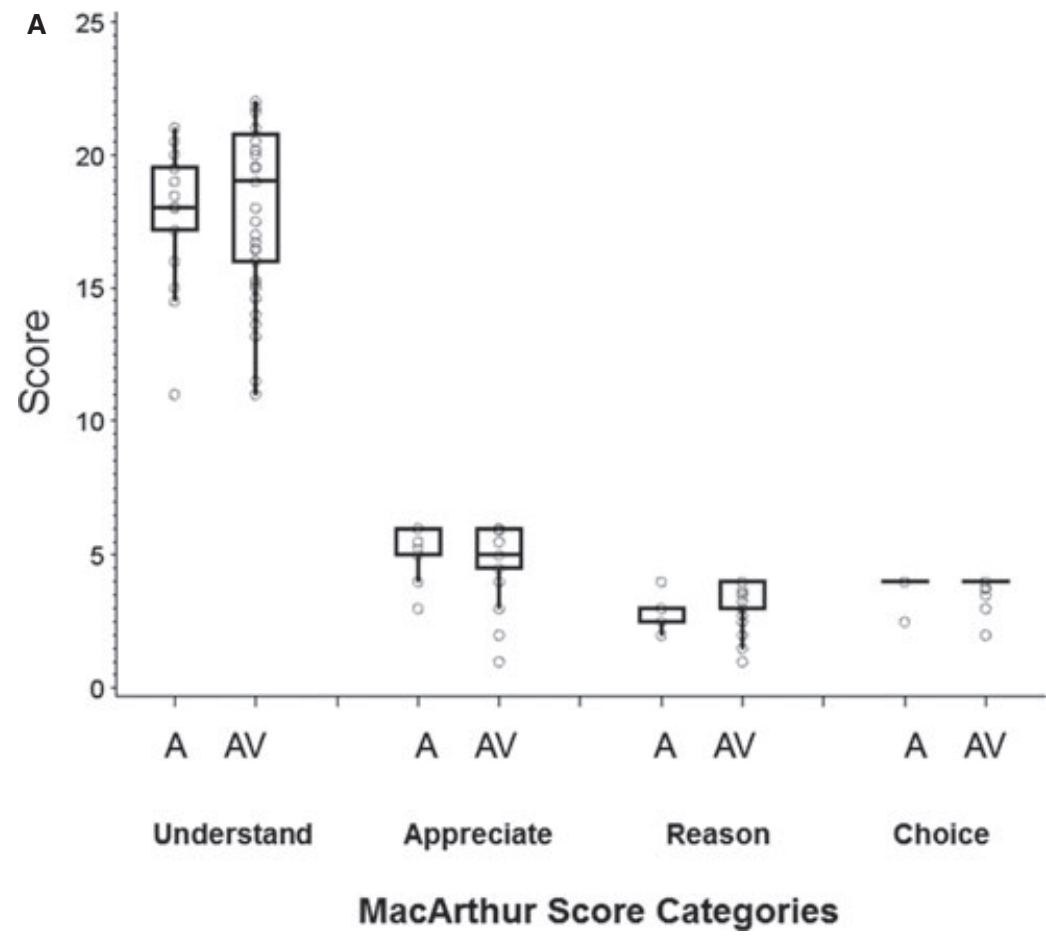

B

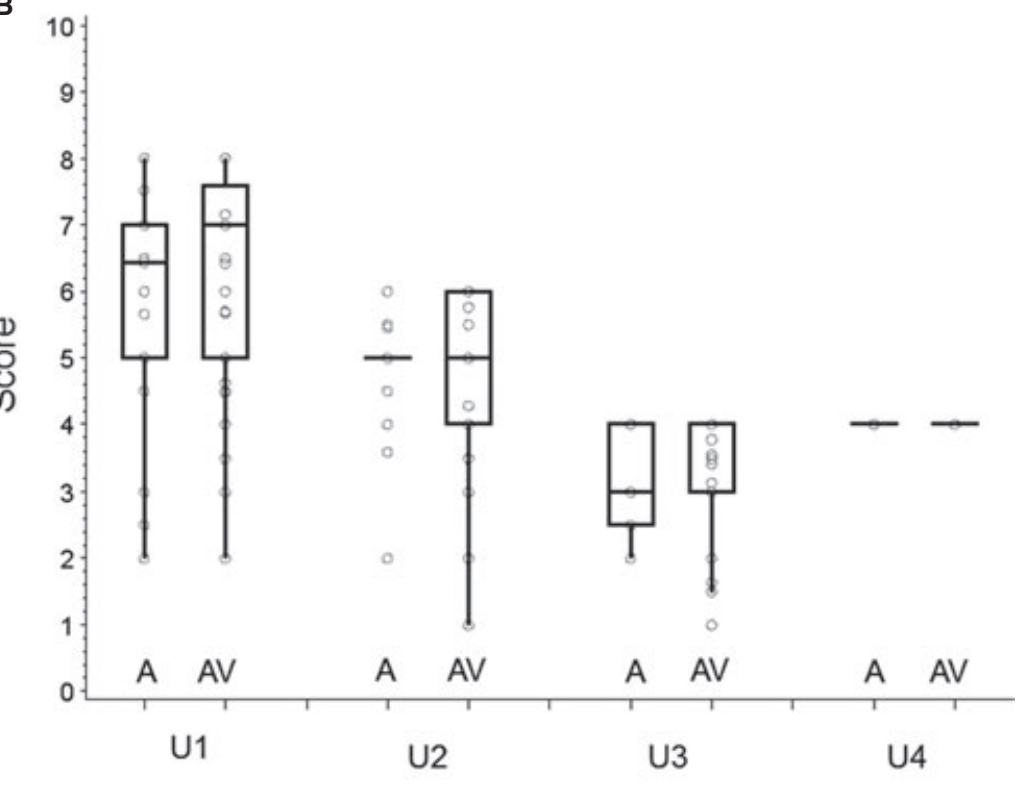

Components of Understanding

experience was "very" or "pretty stressful" $(39 \%$ vs. $68 \%, \mathrm{p}=0.006$ ).

\section{Discussion}

The prospective enrollment of living liver donors (LDs) in the A2ALL consortium provided an opportunity to develop and evaluate a standardized educational tool and quantitative assessment for competence-related abilities (MacLiver) in the setting of living liver donation. This was accomplished using a self-administered program designed
Fig. 1. (a). Boxplot distributions of scores, with a circle for each observation overlaid for each component of competence (each circle may represent more than one data point), separately for those scored using audio information only $(\mathrm{A}, \mathrm{n}=17)$ and audio plus video information $(\mathrm{AV}, \mathrm{n}=76)$. Each item was scored as 0,1 , or 2 , and the subscale scores are the sum of item scores. Understanding (11 items), Appreciation (three items), Reasoning (two items), and Final Choice (two items). Boxes include the 25 th to 75 th percentiles; the middle line indicates the median. Whiskers extend from each end of the box to the farthest data point within 1.5 times the interquartile range (IQR). (b) Boxplot distributions of scores with a circle for each observation overlaid (each circle may represent more than one data point) for each component of Understanding, separately for those scored using audio information only $(\mathrm{A}, \mathrm{n}=17)$ and audio plus video information ( $\mathrm{AV}, \mathrm{n}=76$ ). Each item was scored as 0,1 , or 2, and the subscale scores are the sum of item scores. U1: Understanding the purpose and components of the evaluation process (four items), U2:

Understanding the purpose and method of this MacLiver research (three items), U3: Understanding the risks and benefits of undergoing the donor evaluation process (two items), and U4: Understanding the right to stop the evaluation at any time without consequence (two items). Boxes include the 25 th to 75 th percentiles; the middle line indicates the median. Whiskers extend from each end of the box to the farthest data point within 1.5 times the interquartile range (IQR).

for tablet computers, created specifically for the study. We aimed to develop a tool to augment center-specific donor evaluations by identifying areas of reduced donor comprehension and possible issues with donor competence to consent to liver donation.

The cohort of participants in the MacLiver process, although only $23 \%$ of the total prospective donor population, were similar to those who did not participate due to refusals and technical problems. There were no statistically or clinically meaningful 
Table 3. Performance on the MacLiver by characteristics of the donors $(\mathrm{N}=93)$

\begin{tabular}{|c|c|c|c|c|}
\hline Characteristic & $\begin{array}{l}\text { Understanding }(\max =22) \\
\text { Mean } \pm \text { SD }\end{array}$ & $\begin{array}{l}\text { Appreciation }(\max =6) \\
\text { Mean } \pm \mathrm{SD}\end{array}$ & $\begin{array}{l}\text { Reasoning }(\max =4) \\
\text { Mean } \pm \mathrm{SD}\end{array}$ & $\begin{array}{l}\text { Final Choice }(\max =4) \\
\text { Mean } \pm S D\end{array}$ \\
\hline \multicolumn{5}{|l|}{ Overall } \\
\hline Age & $18.1 \pm 2.6$ & $5.1 \pm 1.0$ & $3.1 \pm 0.8$ & $3.8 \pm 0.5$ \\
\hline$\leq 38 \mathrm{yr}$ & $17.9 \pm 2.8$ & $4.9 \pm 1.0$ & $3.1 \pm 0.7$ & $3.9 \pm 0.5$ \\
\hline$>38 \mathrm{yr}$ & $18.4 \pm 2.4$ & $5.2 \pm 1.0$ & $3.1 \pm 0.9$ & $3.8 \pm 0.5$ \\
\hline \multicolumn{5}{|l|}{ Sex } \\
\hline Female & $18.1 \pm 2.6$ & $5.0 \pm 1.0$ & $3.2 \pm 0.7$ & $3.9 \pm 0.5$ \\
\hline Male & $18.1 \pm 2.7$ & $5.1 \pm 1.1$ & $3.0 \pm 0.8$ & $3.8 \pm 0.5$ \\
\hline \multicolumn{5}{|l|}{ Ethnicity } \\
\hline Hispanic & $17.5 \pm 3.1$ & $5.0 \pm 1.1$ & $3.2 \pm 0.8$ & $3.8 \pm 0.7$ \\
\hline Non-Hispanic & $18.2 \pm 2.6$ & $5.1 \pm 1.0$ & $3.1 \pm 0.8$ & $3.8 \pm 0.5$ \\
\hline \multicolumn{5}{|l|}{ Race } \\
\hline Non-white & $17.0 \pm 3.0$ & $5.1 \pm 0.5$ & $3.0 \pm 0.0$ & $3.9 \pm 0.2$ \\
\hline White & $18.2 \pm 2.6$ & $5.1 \pm 1.1$ & $3.1 \pm 0.8$ & $3.8 \pm 0.5$ \\
\hline \multicolumn{5}{|l|}{ Education $^{\mathrm{a}}$} \\
\hline >High school & $19.0 \pm 2.1^{\mathrm{b}}$ & $5.2 \pm 0.9$ & $3.3 \pm 0.8^{\mathrm{b}}$ & $3.8 \pm 0.5$ \\
\hline$\leq$ High school & $17.5 \pm 2.7$ & $4.9 \pm 1.2$ & $2.9 \pm 0.7$ & $3.8 \pm 0.5$ \\
\hline \multicolumn{5}{|c|}{ Relatedness to recipient ${ }^{\mathrm{a}}$} \\
\hline Biological & $18.1 \pm 2.7$ & $5.1 \pm 1.0$ & $3.1 \pm 0.8$ & $3.8 \pm 0.5$ \\
\hline Non-biological & $18.1 \pm 2.6$ & $5.0 \pm 1.1$ & $3.1 \pm 0.7$ & $3.8 \pm 0.4$ \\
\hline \multicolumn{5}{|c|}{ Accepted for donation } \\
\hline Accepted & $18.2 \pm 2.6$ & $5.1 \pm 1.0$ & $3.1 \pm 0.8$ & $3.8 \pm 0.5$ \\
\hline Not accepted & $18.0 \pm 2.7$ & $5.0 \pm 1.1$ & $3.2 \pm 0.8$ & $3.9 \pm 0.4$ \\
\hline \multicolumn{5}{|l|}{ Donated status } \\
\hline Donated & $18.2 \pm 2.6$ & $5.0 \pm 1.0$ & $3.1 \pm 0.8$ & $3.8 \pm 0.6$ \\
\hline Not donated & $18.1 \pm 2.6$ & $5.1 \pm 1.0$ & $3.1 \pm 0.8$ & $3.9 \pm 0.4$ \\
\hline \multicolumn{5}{|c|}{ Cause of liver failure in intended recipient } \\
\hline Alcohol & $18.6 \pm 1.5$ & $5.4 \pm 0.8$ & $3.3 \pm 0.7$ & $3.9 \pm 0.3$ \\
\hline Not alcohol & $18.1 \pm 2.7$ & $5.0 \pm 1.0$ & $3.1 \pm 0.8$ & $3.8 \pm 0.5$ \\
\hline
\end{tabular}

SD, standard deviation. Bold values indicate education level beyond high school was associated with significantly higher Understanding and Reasoning scores.

aEducation missing/unknown for $n=17$; relatedness to recipient missing/unknown for $n=20$.

${ }^{b}$ Education effect for Understanding, $p=0.006$; Appreciation, $p=0.1556$; Reasoning, $p=0.0241$; Final Choice, $p=0.8432$.

differences in MacLiver performance based on donor demographics or disposition, beyond education. Also, we found no MacLiver differences when comparing biological vs. non-biological potential donors, spouses vs. other categories, or alcohol as a cause of recipient liver failure vs. other categories.

We were pleased to find that all prospective donors could express their understanding that they had the right to refuse donation and further evaluation at any time and do so without consequence. Nearly all could express a clear final choice about their decision. As expected, there was greater variability in Appreciation and Reasoning than in other domains, relative to the respective numbers of questions, which may be due to subjectivity in the scoring of these qualitative responses.

Education was associated with certain competence-related domains. Those with a higher level of education obtained higher MacLiver Understanding and Reasoning scores than those with less education, as has been observed with the MacCAT$\mathrm{CR}$ in other settings (23). In addition to the impact of baseline education on scores, remedial education to enhance Understanding and Appreciation positively affected MacCAT-CR performance in depressed (24) and schizophrenic (25) participants assessed for competence to undergo treatment or consent to research.

Completing the MacLiver did not appear to affect prospective LDs' satisfaction post-donation. Those who took the MacLiver did report less stress about the donation, but this could reflect either a causal effect or a selection of more resilient donors who consented to undergo the MacLiver. Whether personality traits differ between those willing to consent to an added research component and those who do not could be examined in a future study using a tool such as the NEO PI-3 (26). In general, however, it is not so surprising that the MacLiver, which was a small part of the entire donor evaluation process, had little lasting effect on donor preparedness or attitudes about donation.

The MacLiver provided insight into how prospective LDs with no prior education from the donor evaluation team demonstrate their competence-related abilities to understand, appreciate, 
reason, and express a clear choice in response to standardized preliminary education. It is premature to qualify these data as "normative," but this sample was demographically consistent with the large range of prospective live LDs seen in our multicenter retrospective experience and in other reports $(13,14,16,17)$. Given that these abilities, as components of competence, are necessary for regulatory compliance, these data may offer useful guidance on improving the process of donor assessment.

Individual performances on the MacLiver revealed considerable variability. Although no individual scored more than 1 standard deviation below all domain means, several clear outliers appeared within specific domains. Such individuals may be a group whose performance warrants more in-depth evaluation; a tailored, individualized approach to education; or further assessment. The latter is currently under development (EJ Gordon, 1R03DK091786-01).

Among the MacLiver participants, we expected a low exclusion rate due to competence-related deficiencies because they were required to provide written informed consent before performing the MacLiver module. Across the nine participating transplant centers, the local standard of medical, psychosocial, and psychiatric evaluations yielded only two prospective LDs who were ruled out for "psychosocial contraindications." These two scored near or above the sample mean on the MacLiver domains, illustrating that performance on competence-related measures is only one of several issues that may lead otherwise medically suitable participants to be declined as donors. Although the MacLiver provides useful clinical information, it does not replace clinical judgment. It does, however, reduce the potential for evaluator bias in determining donor eligibility, providing more rigorous protection to this donor population.

Our experience with the MacLiver can provide guidance for future implementations. Early administration of the MacLiver can yield a "needs assessment" of areas important to competence, which is consistent with the intent of the MacCAT-CR (15) and its use in other studies $(16,23-25)$. Use of the tablet to standardize the educational component at a prospective donor's initial visit can be timesaving for center personnel and ensure that all prospective donors receive uniform instruction. Timely provision of MacLiver scores to center staff can highlight the need for additional education to aid the potential LD in decision making. Retention of knowledge could be tested at a second visit to assess how well a prospective donor sustains competency over time. Increased educational consistency, protecting prospective LDs by identifying atypical performance, and timely assessment with minimal investment of center resources are the main strengths of this method.

A bitter lesson from our study was the importance of thoroughly testing computer technology before use in the clinic. Although we had reviewed and approved the MacLiver educational segments, which were well done and well received, we did not sufficiently test the data acquisition and upload features. Centers had a variety of technical issues, some of which were difficult to solve. Delays occurred due to communication lags between the data coordinating center, the clinical centers, and Clinaero. In spite of these problems, we would still recommend a video interface for the educational components, which was successful in our implementation. For the query components, the video recording of subjects' answers, which require scoring by a psychologist, may not be feasible in terms of time or cost in a transplant clinic. One costeffective alternative would be a short answer or multiple-choice test, preferably by computer, so that scores could be immediately sent to relevant transplant staff for planning the next step of the donor evaluation process.

There are important limitations to the study. First, the MacCAT-CR format on which the MacLiver is based was developed for live interaction with an experienced interviewer, wherein participants have repeated opportunity to demonstrate the extent of their decisional abilities (27). Although probing an individual's response could reveal either more or less comprehension, uncovering knowledge deficits and re-disclosing information are likely to result in higher scores via the "teach-back" method (28). With noninteractive computerized administration, this advantage was lost. Second, the technology used was not accessible to all patients due to a lack of familiarity with computers, limitations in communication ability, or language barriers (29). Third, the approach complicated the clinical flow. Study coordinators reported that the earlier arrival time required to take the MacLiver before clinical visits was a primary deterrent for the $77 \%$ who did not participate. Lastly, the technology had failures in recording and downloading responses, and some users could not navigate the system effectively. These issues combined to create a substantial loss of potential participants for the MacLiver evaluation. Although we ascertained that the subset that attempted the MacLiver did not differ from the overall cohort on any measured dimension, the possibility of unmeasured differences cannot be excluded. In future implementations, computer literacy and language capacity 
could be accommodated, for example, by provision of a brief computer training program or providing translated versions for common nonEnglish languages (30). An advantage of the MacLiver is that it provided a uniform instructional approach to potential donors at all nine A2ALL clinical centers. If updated to include current federally mandated, consensus driven information, it may be useful as a preliminary education tool that could be viewed at the start of an initial prospective LD clinic visit.

In conclusion, we have evaluated a novel approach for standardized education and assessment of competence in prospective LDs. Potential donors who were judged competent by conventional local assessments generated a range of presumably acceptable MacLiver scores, but also included outliers who may need tailored evaluation and education. Despite methodological difficulties, this is an important first step in implementing standardized education and preparation for competence assessment among potential LDs.

\section{Authors' contributions}

Jason Freeman participated in conducting the research via hypothesis generation, data collection and analysis, and with the writing and editing of the manuscript. Jean Emond participated in the research design, writing of the manuscript, and the data analysis. Brenda W. Gillespie participated in research design, the writing of the manuscript, and in data analysis. Paul S. Appelbaum and Robert Weinrieb participated in research design and in the writing of the manuscript. Peg Hill-Callahan participated in the writing of the manuscript and in the performance of the research. Elisa J. Gordon participated in the writing of the manuscript. Norah Terrault and Timothy Pruett participated in the research design, writing of the manuscript, and performance of the research. James Trotter participated in the research design, performance of the research, and in the data analysis. April Ashworth participated in the writing of the manuscript and performance of the research. Mary Amanda Dew participated in data analysis and in the writing of the manuscript.

\section{Acknowledgements}

The authors acknowledge the contributions of the following study coordinators, co-investigators, and administrative assistants at each of the participating institutions: Andrea Herman, RN, Carlos Garcia, Michelle Jaramillo, and Rita Lerner at the University of Colorado Denver, Aurora, CO; Janet Mooney at the University of California, Los Angeles, CA; Dulce MacLeod, RN, at the Uni- versity of California, San Francisco, LA; Colleen Green and Royanne Dell, RN, at the University of Virginia, Charlottesville, VA; Patrice Al-Saden at Northwestern University, Chicago, IL; Scott Heese at Columbia University, New York, NY; and Charlotte Hoffman at the Virginia Commonwealth University, Richmond, VA. The patients participating in this trial were enrolled in the National Institutes of Health (NIH)-sponsored Adult-toAdult Living Donor Liver Transplantation Cohort Study. This study was supported by the National Institute of Diabetes and Digestive and Kidney Diseases (NIDDK) through cooperative agreements (NIDDK grant nos.: U01-DK62536, U01-DK62444, U01-DK62467, U01DK62483, U01-DK62484, U01-DK62494, U01-DK62496, U01-DK62498, U01-DK62505, and U01-DK62531). The trial was also funded by the research grants from Schering-Plough, through a cooperative research and development agreement with NIH-NIDDK, and through a clinical trial agreement between Ortho-Biotech and NIHNIDDK. This study was supported by the NIDDKD through cooperative agreements (listed in parentheses). Additional support was provided by the Health Resources and Services Administration and the American Society of Transplant Surgeons.

The authors would like to especially thank Jennifer McCready-Maynes, Medical Editor of Arbor Research Collaborative for Health in Ann Arbor, MI for her efforts to bring this article to publication.

\section{SDC, Appendix \\ MacArthur Competence Scale, script adapted for the Adult-to-Adult Living Donor Liver Transplantation Cohort Study (A2ALL): MacLiver}

\section{Understanding -1 (U-1)}

Disclosure: Purpose of the evaluation process and what its components are:

"People who are thinking of donating part of their liver to another person first must go through an evaluation process. The goals of the evaluation are to be sure that (i) the donor is healthy and can undergo major surgery and (ii) the donor's liver is the right match for the recipient. Potential donors will undergo a thorough history and physical examination, interviews with health care professionals, and a variety of $\mathrm{x}$-ray and blood tests. Also, because donating part of a liver can impact donors' lives in ways beyond their physical health, social workers and others will talk with donors and their families about the emotional and social consequences."

U-1a "What has to occur before someone can donate part of their liver to another person?

Answer: An evaluation process (if further details mentioned at this point, credit could also be applied to subsequent answers to $\mathrm{U}-1 \mathrm{~b}, 1 \mathrm{c}$, and $1 \mathrm{~d}$ below as appropriate). 
$\mathrm{U}-1 \mathrm{~b}$ "What are the goals of the evaluation process?"

Answer: See if potential donors are (i) healthy enough to have surgery and (ii) if their livers are good matches for the recipients.

Two points for both concepts: 1 point for one concept and 0 points if neither concept expressed.

U-1c "What will the evaluation process involve?"

Answer: History and physical, blood and lab tests, $\mathrm{x}$-rays. Other tests may also be mentioned (e.g., ultrasound). Two points for both $\mathrm{H}$ and $\mathrm{P}$, and one or more other tests; 1 point for either $\mathrm{H}$ and $\mathrm{P}$ or 1 test; 0 points if neither $\mathrm{H}$ and $\mathrm{P}$ or any other tests mentioned.

U-1d "What other things will occur?"

Answer: Interviews for personal and social assessments (or specifically identifying meetings with a social worker, psychologist, and/or psychiatrist).

Two points for identifying those portions of the evaluation are non-medical in nature as above: 1 point for adding another appropriate medical test at this point and 0 points if neither.

\section{Understanding-2 (U-2)}

Disclosure: Purpose of this study: Research on decision making about the donation:

"In addition to performing liver transplants, this center is part of a research group that is trying to learn about why people decide to donate parts of their livers, and how donation affects their long-term quality of life. This involves asking all potential donors a series of questions during the evaluation process and again after the transplant takes place-even if they don't end up donating part of their liver."

$\mathrm{U}-2 \mathrm{a}$ "What is this transplant center trying to learn about potential LDs?"

Answer: Determine (i) their motives and (ii) long-term outcomes.

Two points for both concepts: 1 point for one concept and 0 points if neither concept.

U-2b "How will this information be gathered?"

Answer: All potential donors will be assessed through the administration of standardized tests.
U-2c "Will everyone be asked to answer these questions, even if they don't donate part of their liver?"

Answer: Yes.

\section{Understanding- 3a (U-3a)}

Disclosure of possible Benefits:

"There are several potential personal benefits from being considered as a LD. By undergoing a thorough medical evaluation, it is possible that previously unknown disorders might be identified and treated. In addition, if the donor is found to be healthy and goes through with the liver donation, the donor may derive a deep personal satisfaction from giving the chance for continued life to another person."

U-3a "What possible benefit could come from being evaluated for liver donation"?

Answers: 1. Personal satisfaction.

2. Possible discovery of an otherwise unknown disorder.

Two points for both concepts: 1 point for one and 0 points if neither.

\section{Understanding-3b (U-3b)}

Disclosure of Risks:

"Although every effort is made to assure that the risk of liver donation is minimal, a variety of risks are taken by the LD. In the US, there have been two deaths in the roughly 1000 liver donations that have been done to date. Moreover, donors experience the pain and discomfort that comes with a major abdominal operation."

U-3b "What sorts of risks might a donor experience?"

Answers: 1. Death

2. Pain and discomfort from major surgery.

Others may be mentioned, but the specific possibilities of death and certainty of pain must be identified.

Two points for both concepts: 1 point for one and 0 points if neither.

\section{Understanding-4a (U-4a)}

Disclosure of the Right to refuse to be a donor without consequence:

"No one has to donate a portion of his or her liver, even if they have begun the evaluation 
process. Potential donors can decline to proceed with any further testing or with the operation at any time. No one will be told the reason why a potential donor decided not to proceed and there will be no charge for the evaluation that was done."

U-4a and 4b: "Once entering the evaluation process, does a potential donor have to donate part of their liver? What will happen to them if they decide not to donate?"

Answer: 1. Absolute free choice for donation.

2. No adverse consequence of not donating.

Two points for both concepts: 1 point for one and 0 points if neither.

\section{Appreciation (A 1-3):}

A-1 "Do you believe that the primary reason for donating your liver is for your own benefit?"

Answer: No personal physical benefit.

A-2 "Do you think that something injurious or painful could happen if you donated your liver?"

Answer: Reasonable risk that something might happen- low risk of death, $100 \%$ risk of pain

Two points if answer included 1 or more specific outcomes: 1 point for simple answer "yes" and 0 points if LD did not express risk.

A-3 "What do you believe would happen if you were to decide not to donate your liver?"

Answer: Nothing to the donor, may speak about family or recipient.

\section{Expressing a Final Choice (E)}

E-1 "You have expressed an interest in being a LD. Do you think that you are likely to want to proceed on towards liver donation or not likely to donate?"

Record answer (must be a clear statement to receive full credit).

\section{Reasoning (R)}

R-1 [Consequential/Comparative Reasoning] "Tell me why you thought that option was the right choice for you."

Record answer (must include a clear statement about what facts, potential risks/benefits, and beliefs were considered in expressing a clear rationale to receive full credit).
R-2 [Generating Consequences] "I have told you about some of the possible benefits and risks and discomforts of donating a portion of your liver. The major benefit is the personal satisfaction that you have helped someone that would die without a liver transplant. The risks include the pain and discomfort that you will experience and the very small chance that you could die. How do you think liver donation would affect your everyday life, including your job, your life at home, and your family relationships"?

Answer: At least two effects on everyday life.

Two points for two or more effect: 1 point for one effect and 0 points if expressed belief that nothing would change.

\section{Expression of final choice}

E-2 "A few minutes ago you expressed a choice about whether to proceed on with the process of liver donation. What do you think now that we have discussed everything? What do you want to do now?"

Record answer (must be a clear statement to
receive full credit).

\section{Appendix (The A2ALL Study Group)}

The A2ALL Study Group includes Northwestern University, Chicago, IL; University of CaliforniaLos Angeles, CA; University of California-San Francisco, CA; University of Colorado Health Sciences Center, Denver, CO; University of North Carolina, Chapel Hill, NC; Epidemiology and Clinical Trials Branch, Division of Digestive Diseases and Nutrition, National Institute of Diabetes and Digestive and Kidney Diseases, National Institutes of Health, Bethesda, MD; University of Michigan, Ann Arbor, MI; Department of Surgery, Columbia Presbyterian Medical Center, New York, NY; University of Pennsylvania, Philadelphia, PA; Department of Internal Medicine, University of Virginia, Charlottesville, VA; and Virginia Commonwealth University, Richmond, VA. The following individuals were instrumental in the planning, conduct, and/or care of patients enrolled in this study at each of the participating institutions, Columbia University Health Sciences, New York, NY (DK62483): principal investigator, Jean C. Emond, MD; coprincipal investigator, Robert S. Brown, Jr., MD, $\mathrm{MPH}$; study coordinators, Scott Heese, BA, and Taruna Chawla, MD; Northwestern University, Chicago, IL (DK62467): principal investigator, Michael M.I. Abecassis, MD, MBA; co-principal investigator, Laura M. Kulik, MD; study coordina- 
tor, Patrice Al-Saden, RN, CCRC; University of Pennsylvania Health System, Philadelphia, PA (DK62494): principal investigator, Abraham Shaked, MD, PhD; co-principal investigator, Kim M. Olthoff, MD; study coordinators, Brian Conboy, PA, MBA, and Mary Shaw, RN, BBA; University of Colorado Health Sciences Center, Denver, CO (DK62536): principal investigator, Gregory $\mathrm{T}$. Everson, MD; co-principal investigator, Igal Kam, MD; study coordinator, Andrea Herman, RN; University of California Los Angeles, Los Angeles, CA (DK62496): principal investigator, Johnny C. Hong, MD; co-principal investigator, Ronald W. Busuttil, MD, PhD; study coordinator, Janet Mooney, RN, BSN. The principal investigator for LADR was Sammy Saab, MD, University of California San Francisco, San Francisco, CA (DK62444): principal investigator, Chris E. Freise, MD, FACS; co-principal investigator, Norah A. Terrault, MD; study coordinator, Dulce MacLeod, RN; University of Michigan Medical Center, Ann Arbor, MI (DK62498): principal investigator, Robert M. Merion, MD; data coordinating center staff, Anna S.F. Lok, MD, Akinlolu O. Ojo, MD, PhD, Brenda W. Gillespie, PhD, Margaret Hill-Callahan, BS, LSW, Terese Howell, BS, CCRC, Lisa Holloway, BS, CCRC, Monique Lowe, MS, Abby Smith, BA, and Abby Brithinee, BA; University of North Carolina, Chapel Hill, NC (DK62505): principal investigator, Paul H. Hayashi, MD, MPH; study coordinator, Tracy Russell, MA; University of Virginia (DK62484): principal investigator, Carl L. Berg, MD; study coordinator, Jaye Davis, RN, and Colleen Green, PA. The principal investigator for LADR was Abdullah M.S. Al-Osaimi, MD; Medical College of Virginia Hospitals, Virginia Commonwealth University, Richmond, VA (DK62531): principal investigator, Robert A. Fisher, MD, FACS; co-principal investigator, R. Todd Stravitz, MD; study coordinators, April Ashworth, RN, Andrea Lassiter, BS, and Charlotte Hoffman, RN. The principal investigator for LADR was Mitchell Shiffman, MD; Division of Digestive Diseases and Nutrition, National Institute of Diabetes and Digestive and Kidney Diseases, Bethesda, MD: James E. Everhart, MD, MPH, Averell Sherker, MD, and Jay H. Hoofnagle, MD.

\section{References}

1. Berg CL, Gillespie BW, Merion RM et al. A2AlL Study Group. Improvement in survival associated with adult-toadult living donor liver transplantation. Gastroenterology 2007: 6: 1806 .

2. Segev Dl, Muzanle AD, Caffo BS et al. Perioperative mortality and long-term survival following live kidney donation. JAMA 2010: 303: 959.
3. Trotter JF, Adam R, Lo CM, Kenison J. Documented deaths of hepatic lobe donors for living donor liver transplantation. Liver Transpl 2006: 12: 1485.

4. Ratner LE, Sandoval PR. When disaster strikes: death of a living organ donor. Am J Transplant 2010: 10: 2577.

5. Delmonico FL. Vancouver forum on the live lung, liver, pancreas, and intestine donor. Transplantation 2006: 82: 1245.

6. Pruett Tl, Tibell A, Alabdulkareem A et al. The ethics statement of the Vancouver Forum on the live lung, liver, pancreas, and intestine donor. Transplantation 2006: 81: 1386.

7. Barr ML, Belghiti J, Villamil FG et al. A report of the Vancouver Forum on the care of the live organ donor: lung, liver, pancreas, and intestine data and medical guidelines. Transplantation 2006: 81: 1373.

8. Appelbaum PS, Grisso T. MacArthur Competence Assessment Tool for Clinical Research (MacCAT-CR). Sarasota, FL: Professional Resource Press, 2001.

9. Faden R, Beauchamp TL. A History and Theory of Informed Consent. New York: Oxford University Press, 1986.

10. Rodrigue JR, Pavlakis M, Danovitch GM et al. Evaluating living kidney donors: relationship types, psychosocial criteria, and consent processes at US transplant programs. Am J Transplant 2007: 7: 2326.

11. Parekh AM, Gordon EJ, Garg AX, Waterman AD, Kulkarni S, Parikh CR. Living kidney donor informed consent practices vary between US and non-US centers. Nephrol Dial Transplant 2008: 23: 3316.

12. Housawi AA, Young A, Boudville $\mathrm{N}$ et al. Donor Nephrectomy Outcomes Research (DONOR) Network. Transplant professionals vary in the long-term medical risks they communicate to potential living kidney donors: an international survey. Nephrol Dial Transplant 2007: 22: 3040 .

13. Trotter JF, Wisniewski KA, Terrault NA et al. A2All Study Group. Outcomes of donor evaluation in adult-toadult living donor liver transplantation. Hepatology 2007: 46: 1476 .

14. Trotter JF, Gillespie BW, Terrault N et al. Adult-toAdult Living Donor Liver Transplantation Cohort Study Group. Laboratory test results after living liver donation in the Adult to Adult Living Donor Liver Transplantation Cohort Study (A2ALL). Liver Transpl 2011: 17: 409.

15. Grisso T, Appelbaum PS. Assessing Competence to Consent to Treatment: A Guide for Physicians and Other Health Professionals. New York: Oxford University Press, 1998.

16. Appelbaum PS, Grisso T, Frank E, O’Donnell S, Kupfer DJ. Competence of depressed patients for consent to research. Am J Psychiatry 1999: 156: 1380.

17. Karlawish JHT, Casarett DJ, James BD. Alzheimer's disease patients' and caregivers' capacity, competency, and reasons to enroll in an early-phase Alzheimer's disease clinical trial. J Am Geriatr Soc 2002: 50: 2019.

18. Dunn L, Nowrangi MA, Palmer BW, Jeste DV, Saks ER. Assessing decisional capacity for clinical research or treatment: a review of instruments. Am J Psychiatry 2006: 163: 1323.

19. Simmons R, Marine S, Simmons R. Gift of Life: The Effect of Organ Transplantation on the Individual, Family and Societal Dynamics. New Brunswick, NJ: Transaction Publishers, 1987.

20. Padilla Ma, Divers J, Vaughan LK, Allison DB, TIWARI HK. Multiple imputation to correct for measure- 


\section{MacLiver and organ donation}

ment error in admixture estimates in genetic structured association testing. Hum Hered 2009: 68: 65.

21. Little RJA, Rubin DB. Statistical Analysis with Missing Data, 2nd edn. Hoboken, NJ: John Wiley \& Sons, 2002.

22. Little R, YAU L. Intent-to-treat analysis for longitudinal studies with drop-outs. Biometrics 1996: 52: 1324.

23. Candilis PJ, Fletcher Ke, Geppert CM, Lidz CW, Appelbaum PS. A direct comparison of research decisionmaking capacity: schizophrenia/schizoaffective, medically ill, and non-ill subjects. Schizophr Res 2008: 99: 350.

24. Lapid Mi, Rummans TA, Pankratz VS, Appelbaum PS. Decisional capacity of depressed elderly to consent to electroconvulsive therapy. J Geriatr Psychiatry Neurol 2004: 17: 42 .

25. Carpenter WT, Gold JM, Lahti AC et al. Decisional capacity for informed consent in schizophrenia research. Arch Gen Psychiatry 2000: 57: 533.
26. McCrae RR, Costa PT, Martin TA. The NEO-PI-3: a more readable revised NEO personality inventory. J Pers Assess 2005: 84: 261.

27. Schillinger D, Piette J, Grumbach K et al. Closing the loop: physician communication with diabetic patients who have low health literacy. Arch Intern Med 2003: 163: 83.

28. Institute of Medicine. Speaking of Health: Assessing Health Communication Strategies for Diverse Populations. Washington, DC: National Academy Press, 2002.

29. National Telecommunication and Information AdminIStRATION. A Nation Online: Entering the Broadband Age. 2004; http://www.ntia.doc.gov/reports/anol/index.html. Accessed 2 December 2010.

30. Lai AM, Kaufman DR, Starren J, Shea S. Evaluation of a remote training approach for teaching seniors to use a telehealth system. Int J Med Inform 2009: 78: 732. 